\title{
Contribuições da Abordagem Autopoiética-Enativa ao Conceito de Adaptação Psicológica
}

\author{
Contributions of autopoietic-enactive approach \\ to the concept of psychological adaptation
}

\begin{abstract}
Resumo: A temática da adaptação atravessa a constituição da psicologia. No entanto é apenas com W.James e com o movimento funcionalista norte americano que a adaptação como conceito entra para o vocabulário psicológico. Em função das articulações teóricas e do contexto sócio-cultural, a adaptação surge concebida como ajustamento do organismo ao meio ambiente. Com base nas contribuições da abordagem autopoiética-enativa de H.Maturana e F.Varela este artigo problematiza essa concepção que é ainda hegemônica. Para Maturana e Varela a adaptação aproxima-se das noções de sintonia e composição com o meio.

Palavras-chave: Abordagem autopoiética-enativa. Adaptação. Psicologia.

Abstract: The adaptation thematic crosses the constitution of psychology. However it's only with W.J ames and with North American funcionalism movement that adaptation as concept became a part of psychological vocabulary. Due to theoretical articulations and sociocultural context, the adaptation appears as an adjustment of the organism to the environment. This article problematizes this conception using the approach conceived by H.Maturana and F.Varela about the contributions of autopoietic-enactive. Maturana and Varela's conception of adaptation it is similar to the notions of tunning and composition with the environment. Keywords: Autopoietic-enactive approach. Adaptation. Psychology.
\end{abstract}

\author{
Beatriz Sancovschi \\ Universidade Federal do Rio de Janeiro
}

\section{Seria a Adaptação Sinônimo de Ajustamento?}

A interlocução entre a psicologia e o pensamento de Maturana e Varela tem se mostrado bastante fecunda, inspirando diversas pesquisas. Neste contexto, destacamos os trabalhos do grupo Cognição e Subjetividade do qual fazemos parte. Formado por professores, pesquisadores e alunos de graduação e pós-graduação em psicologia da Universidade Federal do Rio de J aneiro (UFRJ) e da Universidade Federal Fluminense (UFF), este grupo vem, desde os anos de 1990, inovando e renovando as discussões psicológicas através das contribuições dos pesquisadores chilenos. Em especial, procederam uma ampliação do conceito de cognição, introduzindo questões como criação, invenção e política. Temas caros à psicologia como aprendizagem, atenção, linguagem e subjetividade vêm, desde então, sendo repensados e revisados. O livro Políticas da Cognição (KASTRUP; TEDESCO; PASSOS, 2008) reúne uma amostra desses trabalhos. Outro aspecto interessante da articulação entre a psicologia e a abordagem autopoiética-enativa refere-se a possibilidade de releitura de autores clássicos como Piaget (KASTRUP, 1999, ALVAREZ, 1999), Vygotski 
(SANCOVSCHI, 2005, SANCOVSCHI; KASTRUP, 2008) e Moscovici (SANCOVSCHI, 2007). Neste momento trazemos as potentes idéias de Maturana e Varela com o objetivo de redefinir o conceito de adaptação psicológica. A partir da crítica ao paradigma representacional, que singulariza a proposta autopoiética-enativa buscamos contribuições para a recolocação do problema da adaptação. A idéia é afastála da proposta de ajustamento ao ambiente, aproximando-a da noção de composição com o meio.

Embora a temática da adaptação atravesse a constituição da psicologia, é apenas com o movimento funcionalista norte-americado, no final do século XIX e início do XX, que a adaptação como conceito entra para o vocabulário psicológico. Contribui para isso a divulgação e popularidade da teoria da evolução de Charles Darwin. Em função das articulações teóricas e do contexto sócio-cultural que marcam o projeto funcionalista, a adaptação psicológica surge concebida como adaptação de um organismo a um meio ambiente pré-existente. Ferreira e Gutman (2005) ao explicarem o funcionalismo defendem que foi a partir dele, assim como das psicologias diferencial e comparada, que nasce o projeto da psicologia enquanto ciência e, enquanto técnica da adaptação. Afirmam que esse projeto acabou por extrapolar seu domínio de origem, fazendo-se presente na atualidade. Assim concluem que a psicologia tem se apresentado como saber voltado para as práticas de ajustamento. Citamos:

Nesses movimentos, graças ao empuxo darwinista, demarca-se uma psicologia interessada na adaptação, evolução e variação das atividades mentais. Contudo, ao longo da história da psicologia, esse modelo se dissemina, transcende os seus movimentos originais e se dissolve no campo psicológico, dando a uma expressiva parte desse campo sua feição atual enquanto saber voltado para as práticas de ajustamento (FERREIRA; GUTMAN, 2005, p. 122)

No entanto, será que a adaptação é necessariamente sinônimo de ajustamento? Será que a afirmação da psicologia como ciência da adaptação implica em vinculá-la a práticas normalizadoras? Tendo em vista estas questões nos voltamos para a abordagem autopoiéticaenativa. Sem desconsiderar as singularidades dos trabalhos de Humberto Maturana e Francisco Varela procuramos com esta nomenclatura que articula a autopoiese com a enação enfatizar a continuidade de seus trabalhos.

Formulada inicialmente como teoria da autopoiese (MATURANA; VARELA, 1995) e, em seguida como abordagem da enação (VARELA, 1990, VARELA; THOMPSON; ROSCH, 2003), a abordagem autopoiética-enativa nasce no contexto das ciências cognitivas como crítica ao cognitivismo computacional e ao conexionismo. Humberto Maturana e Francisco Varela, biólogos de formação, ao acompanharem as discussões sobre o conhecer travadas no contexto das ciências cognitivas, sentiam-se insatisfeitos. Seus estudos em biologia os levavam a considerar insuficientes os paradigmas informacional e representacional para explicação da cognição viva. Conhecer estava longe de ser processar informações que vêm do meio (inputs) e gerar respostas adequadas (outputs). Além disso, sabiam que do ponto de vista do organismo vivo não existe mundo dado a priori. O mundo e o organismo são configurados concomitantemente através de práticas de conhecimento. Como então pensar a atividade de conhecimento como representação adequada a um mundo pré-existente? Num primeiro momento propuseram a teoria da autopoiese. Com ela buscavam recuperar o sentido vivo ou biológico da cognição. Dessa forma a teoria da autopoiese apresentava-se como uma biologia do conhecimento. Tempos depois, em trabalho independente, Varela concebe a proposta enativa como uma radicalização da autopoiese. O diálogo com a fenomenologia de Merleau-Ponty teve grande importância neste momento. Entre a autopoiese e a enação Varela (1989) propõe a idéia de autonomia para pensar o vivo. A autonomia é assim, um conceito de transição que enfatiza a capacidade que todo ser vivo possui de criar para si suas próprias regras (VARELA, 1989). Desse modo Varela distingue os sistemas autônomos, cujo exemplo seria os seres vivos, dos heterônomos. Nos sistemas heterônomos as regras são dadas pelo exterior. $\mathrm{O}$ exemplo paradigmático de sistemas heterônomos seriam as máquinas de entradas e saídas. Nestes, as regras que determinam o funcionamento são inseridas de fora por um programador.

Tomando por base a crítica da abordagem autopoiética-enativa ao paradigma representacional propomos neste texto repensar o conceito de adaptação psicológica. Vale ressaltar que o percurso de Maturana e Varela pela biologia é de grande valia para nossa reflexão. Antes de avançar, destacamos algumas singularidades da adaptação psicológica em relação à biológica. Abordar o tema da adaptação sob 
o prisma da psicologia implica em estender o conceito para além dos limites da vida e da morte, podendo haver desadaptação com manutenção da vida. É justamente quando um organismo encontra-se vivo que a psicologia entra em cena no sentido de tentar auxiliá-lo a viver melhor. Significa ainda, a partir da distinção entre o enfoque filogenético - desenvolvimento da espécie - e ontogenético - desenvolvimento do ser vivo - , sublinhar que o domínio dos problemas em psicologia converge mais para as questões da adaptação do indivíduo do que da espécie. No caso da adaptação psicológica, é justamente quando a espécie sobrevive, ou seja, está adaptada segundo os parâmetros da biologia, que a psicologia é chamada a explicar o problema da adaptação e, principalmente, o da desadaptação do indivíduo.

\section{A Adaptação na Psicologia}

O recurso à história da psicologia permite localizar alguns dos encontros entre a psicologia e a temática da adaptação. Estes foram sendo estabelecidos desde o final do século XIX, até sua efetivação com os trabalhos de W. James e em seguida com o movimento funcionalista. A psicologia científica teve sua origem no final do século XIX, na Europa, com os estudos de W. Wundt sobre a percepção e o conhecimento. Seu interesse era, através do método científico, estudar a experiência imediata. O objetivo, como formula Canguilhem (1973), era explicar porque nosso espírito, ao voltar-se para o mundo para conhecê-lo, é obrigado a enganar-se. Citamos: "A psicologia se constitui, pois, como um empreendimento de desculpa do espírito. Seu projeto é o de uma ciência que, face à física, explica porque o espírito é por natureza obrigado a enganar inicialmente a razão relativamente à realidade" (CANGUILHEM, 1973, p. 109-110). Paralelamente a essa psicologia experimental, Wundt desenvolveu o que ele denominou Psicologia dos Povos. Esse duplo interesse revela uma concepção da psicologia como uma ciência entre as ciências naturais e culturais. No entanto a psicologia com orientações antropológicas ficou em segundo plano, sendo recuperada com o surgimento da psicologia social. Assim, nesse primeiro momento, a psicologia científica ficou conhecida como a ciência que toma para si o estudo dos erros, enganos e ilusões que entram em cena no processo cognitivo. Aí ela se atém e é movida por questões de ordem epistemológica.

Titchener, discípulo de Wundt, avançou em relação a seu mestre, definindo como objeto da psicologia "[ . . . ] a experiência dependente de um sujeito, sendo este concebido como um puro organismo e, em última análise, como um sistema nervoso [ . . . ]" (FIGUEIREDO, 2002, p. 61). Titchener funda o Estruturalismo. Ao estudar os conteúdos mentais, concebe-os como elementos que se associam, segundo leis, e se relacionam a certas condições fisiológicas (SCHULTZ; SCHULTZ, 1992). Cabia, portanto, à psicologia definir os elementos dos conteúdos mentais, descobrir suas leis de associação e suas relações com os processos fisiológicos. Nesse sentido Titchener purificou a psicologia, filiando-a apenas às ciências naturais (FIGUEIREDO; SANTI, 2002, CANGUILHEM, 1973). É nesse momento, pelas mãos de Titchener, que a psicologia, como ciência natural, entra no território norte-americano.

Nos Estados Unidos a psicologia encontra um clima intelectual muito distinto do da Europa. Dentre os motivos destacam-se as diferentes configurações sociais em virtude do forte desenvolvimento urbano que começa ocorrer em meados do século XIX, além do avanço industrial, das novas relações de trabalho e da expansão do sistema escolar. Nas palavras de Schultz e Schultz (1992, p. 146): “O povo dos EUA estava voltado para o prático, o útil e o funcional, e a psicologia americana, em seus estágios pioneiros, refletia essas qualidades". A ênfase pragmática da psicologia norte-americana faz com que ela se oponha às psicologias européias de Wundt e também à de Titchener, no que diz respeito a seus objetos de estudo. No entanto, conserva a filiação às ciências naturais e mantém seu caráter experimental (SCHULTZ; SCHULTZ, 1992).

Ao entrar no novo continente, a psicologia deixa de ser feita apenas nos laboratórios, passando a intervir junto aos sujeitos individuais e em suas práticas. Citamos Ferreira e Gutman (2005, p. 123): “É nesse contexto que a psicologia passou a ter papel ativo, classificando, selecionando e ajustando os indivíduos a esses novos espaços - as escolas e as fábricas - e auxiliando no bom uso da sua liberdade nesse admirável mundo novo". A psicologia norteamericana ficou conhecida como psicologia funcional ou Funcionalismo. Seu interesse era estudar a mente como um processo cujo fim permitiria a adaptação do organismo ao seu 
ambiente. Suas indagações restringiam-se ao plano da utilidade e funcionalidade. A teoria da evolução de Charles Darwin, os estudos de Francis Galton e os trabalhos de psicologia animal contribuíram para o estabelecimento de uma postura e de um olhar funcionalista (SCHULTZ; SCHULTZ, 1992).

Entre o estruturalismo de Titchener e o movimento funcionalista, encontramos os trabaIhos de W. James. Embora não seja enquadrado entre os autores funcionalistas, James contribui para esse movimento desenvolvendo idéias que seriam centrais para a nova psicologia (SCHULTZ; SCHULTZ, 1992, FERREIRA; GUTMAN, 2005). Em seu livro Princípios de Psicologia, publicado em 1890, James defende como objeto da psicologia o estudo das pessoas vivas em sua adaptação ao ambiente. Neste sentido, rompe com a tradição estruturalista e formula o que seria mais adiante o preceito básico da nova psicologia. Para ele os processos mentais (a consciência) deveriam ser estudados de modo pragmático, sob o ponto de vista de sua utilidade. Schultz e Schultz explicam (1992, p. 154): “Ele [James] acreditava que a consciência tem de ter alguma utilidade biológica, pois do contrário não teria sobrevivido. O propósito ou função da consciência é capacitar-nos a nos adaptar ao ambiente [ . . . ]".

O encontro entre a psicologia e a teoria da evolução alterou significativamente o desenvolvimento ulterior da psicologia teórica, bem como criou condições para a psicologia prática. Dentre os muitos conceitos e idéias da teoria da evolução que foram incorporados à psicologia, encontra-se o de adaptação. Para essa nova psicologia os processos cognitivos desempenham uma função adaptativa. A percepção, a inteligência, a aprendizagem têm como objetivo ou finalidade contribuir para a adaptação dos indivíduos. Uma vez que os processos cognitivos conservam-se ao longo da história, eles devem desempenhar um papel na evolução humana, permitindo a sobrevivência do homem em seu ambiente.

Canguilhem (1976) adverte que a origem de um conceito determina seu uso e esse, por sua vez, determina o sentido. A psicologia responsável pela transposição conceitual da noção de adaptação era uma ciência que almejava a objetividade. Filiada unicamente às ciências naturais, era fortemente marcada pela perspectiva pragmática. Interessava-se principalmente pelas possíveis aplicações da psico- logia e foi uma das fontes de inspiração para a psicologia comportamental. O behaviorismo de J. Watson estabelece a partir do modelo estímulo-resposta (S-R) que o meio determina o comportamento do organismo em função dos estímulos. Assim, formula de modo claro e objetivo aquilo que os funcionalistas já haviam trabalhado. Os behavioristas partem da tese funcionalista de que os processos cognitivos subordinam-se à função adaptativa e avançam, estabelecendo um mecanismo que atribui ao ambiente o controle dos comportamentos. Portanto, quando a noção de adaptação entra na psicologia, ela vem atravessada por essa atmosfera funcionalista, ganhando força com o desenvolvimento do movimento funcionalista e sofrendo os efeitos de outros estudos que se desenvolviam nessa época nos EUA, como os de F. Galton e H. Spencer.

F. Galton interessava-se pelas diferenças individuais na capacidade humana e procurava medi-las através de testes mentais. Ficou conhecido pelo desenvolvimento de uma nova ciência, a qual nomeou Eugenia: "[ . . . ] ciência que trata dos fatores capazes de aprimorar as qualidades hereditárias da raça humana [ ... ]" (SCHULTZ; SCHULTZ, 1992, p. 133). H. Spencer, por sua vez, traduziu a teoria de Darwin em termos sociais, afirmando que o homem e as instituições sociais obedecem a uma lógica evolutiva onde sobrevivem apenas os mais capazes. De acordo com a filosofia spenceriana “ As pessoas, empresas ou instituições que não pudessem adaptar-se ao ambiente eram incapazes de sobreviver, devendo-se permitir que perecessem ou se extinguissem em nome da melhoria da sociedade como um todo" (SCHULTZ; SCHULTZ, 1992, p. 146). Ambos os autores tiveram suas idéias bastante difundidas no cenário intelectual norte-americano porém, suas teorias foram severamente criticadas décadas depois - e continuam sendo - devido ao seu caráter etnocêntrico e preconceituoso.

Em função desse contexto, o conceito de adaptação aproxima-se, em psicologia, das noções de conformação, adequação e ajustamento. Tal fato acaba por marcar as práticas psicológicas. Os campos onde a psicologia prática mais se desenvolveu foram a escola e o trabalho. Justamente aí encontramos uma psicologia fortemente marcada pela concepção de adaptação como ajustamento. Nas palavras de Maria Helena Souza Patto: 
A psicologia nasce como marca de uma demanda: a de promover conceitos, instrumentos 'científicos' de medida que garantam a adaptação dos indivíduos à nova ordem social. Assentada sobre a nova ênfase dos psicólogos experimentais no fenômeno psíquico, a ciência recém-inaugurada deixa clara sua finalidade de adaptação, levada a cabo através da seleção e da orientação no trabalho e na escola (PATTO, 1987, p. 96).

Assim, questionar o conceito de adaptação psicológica entendido como ajustamento e conformação pode contribuir não apenas para as práticas psicológicas, mas também para campos adjacentes à psicologia como é o caso da educação e do trabalho. Neste momento nos concentraremos nas contribuições para a psicologia.

\section{A Adaptação na Abordagem Autopoiética-Enativa}

A partir a década de 1960 o campo das ciências cognitivas ganha espaço no cenário científico. Com o desenvolvimento do cognitivismo computacional, que é em princípio dominante, o vivo e a máquina são tomados como sistemas equivalentes (VARELA, 1990, 1988). O computador é erigido como modelo para o entendimento da cognição. Conhecer passa a ser definido como capacidade de processar informações que vêm do meio (inputs) e gerar respostas adequadas (outputs). De acordo com o cognitivismo computacional conhecer é representar adequadamente o mundo através do processamento simbólico realizado sequencialmente por regras lógicas. Assim, as idéias de processamento de informação e de representação vão se tornando hegemônicas provocando, de acordo com Varela, uma "cegueira em relação ao sentido comum da cognição" (VARELA; THOMPSON; ROSCH, 2003). É interessante observar que essas idéias, colocadas inicialmente pelo cognitivismo computacional, sofreram modificações ao longo dos anos e das propostas de entendimento da cognição - redes conexionistas, auto-organização e propriedades emergentes. Contudo, o pressuposto realista (realismo cognitivo) jamais foi colocado em xeque. Até o aparecimento da abordagem autopoiética-enativa, a crença na existência de um mundo pré-definido que seria representado no processo cognitivo era inquestionável nas ciências da cognição. Ao recusarem a representação, Maturana e Varela revelam o caráter circular e sem fundamento da cognição. Tal formulação repercute sobre o conceito de adaptação, principalmente porque é feita no domínio da biologia do conhecimento.

É preciso diferenciar o sentido forte e fraco de representação (VARELA; THOMPSON; ROSCH, 2003, MATURANA; VARELA, 1995). A representação em sentido forte é atravessada por pressupostos ontológicos - há um mundo pré-existente que serve de fundamento - e epistemológicos - o conhecimento é objetivo uma vez que corresponde ao mundo. Já o sentido fraco, diz respeito a um uso semântico, interpretativo, pragmático, sem compromisso epistemológico ou ontológico. Ele faz parte do uso cotidiano e ocorre por questão de comodidade. O que os biólogos chilenos recusam é a representação em sentido forte, admitindo, porém, o sentido fraco. A abordagem autopoiética-enativa recusa a existência de um mundo pré-existente que informaria ao organismo suas características, sendo representado por ele e possibilitando assim uma ação adequada. Veremos mais adiante como essa discussão a respeito do sentido forte e fraco da representação é transposta para a adaptação, ressignificando-a. Antes, porém, apresentaremos algumas idéias e conceitos da autopoiese e da enação que serão importantes para a compreensão da novidade proposta com seu conceito de adaptação.

O termo autopoiese vem do grego e significa autoprodução. Maturana e Varela lançam mão dessa noção, nos anos de 1970, para definir o vivo em sua especificidade. Defendem que aquilo que o singulariza é sua capacidade de se autoproduzir continuamente (MATURANA; VARELA, 1997, 1995). Varela (1989) propõe a idéia de autonomia. Os sistemas vivos são sistemas autônomos uma vez que não existe nada que os determine ou que os otimize além de sua estrutura e organização. Viver é se autoproduzir nas ações cognitivas concretas. Viver é ser, é fazer e é também conhecer. O conhecimento não é apreendido como abstração mental que possibilitaria a ação. Apenas no fazer, na ação, no viver que o conhecimento, assim como a vida, torna-se possível. Tanto a vida como a cognição pressupõem uma circularidade fundamental que é explicada através da organização autopoiética.

A organização autopoiética singulariza os sistemas vivos. Ela consiste num mecanismo de autoprodução através do qual observamos a ocorrência de variações estruturais que, por sua vez dão forma aos diferentes seres vivos. 
Varela e Maturana recorrem à célula para explicar o mecanismo (MATURANA; VARELA, 1995). Segundo eles ela seria a menor unidade autopoiética $^{1}$, por isso seria mais simples explicar o mecanismo através dela. A autopoiese requer, de saída, o fechamento operacional (clausura operacional), através de uma membrana. A clausura é resultado de múltiplos fatores que, juntos, possibilitam a emergência de limites. Estes definem não só o organismo, com sua organização e estrutura, mas seu meio correspondente. Desse modo não é possível conceber um meio universal e absoluto. O meio, assim como o organismo são co-definidos na ação. O fechamento operacional não significa isolamento: "Clausura não é fechamento" (VARELA, 1989, p. 217). Pelo contrário, constitui a possibilidade de toda e qualquer interação ou contato imediato com o mundo e com outros organismos. Sem isto não existe autoprodução. O isolamento e a rigidez das formas implicam na morte da autopoiese, portanto na morte do organismo.

Embora em termos biológicos a perda da autopoiese conduza o organismo à morte, para a psicologia os problemas começam quando os organismos estão vivos. Assim no contexto da interlocução com a psicologia, a discussão da manutenção da autopoiese deve ser deslocada de um referencial cujo critério seja vida ou morte, para outro cujo critério seja a manutenção ou não da capacidade de criar para si novas regras no viver. Nos termos de CanguiIhem (1982) trata-se da manutenção ou não da normatividade da vida que implica na capacidade de reinventar-se a si e ao mundo.

O conceito de normatividade é concebido por Canguilhem ( 1982) para falar da diferença entre o normal e o patológico. Diz respeito a capacidade que todo o ser vivo tem de criar para si novas normas de vida, de "[ . . . ] instituir novas constantes com valor de norma [ . . . ]" (CANGUILHEM, 1982, p. 172). Diferente

1 Maturana e Varela (1995) concebem as células como sistemas autopoiéticos de primeira ordem. Os organismos metacelulares como sistemas de segunda ordem, uma vez que são compostos por uma reunião de células que, como sistema vivo, cada uma individualmente, tem a possibilidade de manter sua autopoiese. Deixando em aberto a existência de sistemas de terceira ordem, que seriam composições de metacelulares, que por sua vez seriam compostos por sociedades de células. Neste sentido estes autores avançam sobre os limites que definem indivíduo e sociedade. da tese clássica que pensa o patológico como um excesso ou uma falta em relação ao estado normal, Canguilhem (1982) defende que, do ponto de vista do organismo doente, a patologia não significa apenas falta ou excesso, mas principalmente outro funcionamento, outras regras, outro mundo, outra vida. Para ele, a diferença entre o normal e o patológico não reside na presença ou ausência de normas, mas antes na qualidade dessas normas. Propõe então duas qualidades: as normas de valor propulsivo e as normas de valor repulsivo (CANGUILHEM, 1982, p. 167). As primeiras dizem respeito a regras que guardam em si uma dimensão processual, ou seja, são em si mesmas normativas. Já as segundas, uma vez estabelecidas repelem de si toda e qualquer atividade. Embora ambas apresentem-se como possibilidades para os organismos vivos, as de valor propulsivo conservam em si a vida, a processualidade, a inventividade, fazendo parte do comportamento saudável do organismo na medida em que permitem a revinvenção diante de uma perturbação eventual. Já as de valor repulsivo repelem de si a dimensão viva e ativa do ser, constituindo dessa forma o comportamento patológico. Assim, para CanguiIhem, tanto o funcionamento normal quanto o patológico implicam na existência de regras e normas, que, entretanto, são distintas. O ser normal mantém viva a sua capacidade normativa, sendo uma de suas características a possibilidade de viver sobre os limites de suas normas e minimamente infrigí-las. Já o ser patológico, aceita as regras e normas que the são dadas sob pena de não conseguir viver: “O patológico não é ausência de norma biológica, é uma norma diferente, mas comparativamente repelida pela vida" (CANGUILHEM, 1982, p. 113-114). Nesse sentido o normal, o organismo saudável é aquele que consegue viver mantendo a sua normatividade, isto é, produzindo suas regras e normas a medida em que vive. E não aquele que tenta encaixar a sua vida a normas e regras pré-fixadas, exteriores a si: “O doente é doente por só admitir uma norma. Como já dissemos muitas vezes, o doente não é anormal por ausência de norma, e sim, por incapacidade de ser normativo" (CANGUILHEM, 1982, p. 148).

Desse modo, sob o ponto de vista psicológico diríamos com Maturana e Varela e, também com Canguilhem que caso o sistema em seu viver estabeleça uma relação que destrua sua 
autopoiese, ou seja, que destrua sua capacidade de produzir novas regras ou normas de vida, apegando-se a padrões rígidos de comportamento, ele terá perdido sua dimensão viva, uma vez que a vida define-se pelo contínuo movimento de autoprodução. Nesse sentido é que se afirma serem os sistemas vivos unidades de interações subordinadas à manutenção da autopoiese.

A autopoiese revela-se uma produção de si que só se realiza com o outro, seja o mundo material, sejam os outros organismos (outras unidades autopoiéticas). Este contato aparece através do conceito de acoplamento estrutural. $\mathrm{O}$ acoplamento diz respeito a modos de interação entre a estrutura do organismo e a do meio. O acoplamento, uma vez estabelecido, produz variações na estrutura do organismo, criando novas formas de ser e de estar no mundo. Portanto, para a abordagem autopoiética-enativa, a atividade cognitiva não se restringe a uma capacidade cerebral, mas está encarnada no corpo ou, em outros termos, na estrutura do organismo (VARELA, 2003). Uma mudança na estrutura implica na modificação das formas de ser e de conhecer. As mudanças estruturais criam novos campos de sensibilidade que participarão de novos acoplamentos. É importante destacar que neste movimento o breakdown ganha lugar de destaque. O breakdown, por vezes traduzido como colapso (VARELA, 2003), nada mais é do que uma perturbação que acontece em função do próprio movimento autopoiético e coloca em xeque acoplamentos e modos de funcionar anteriores. O resultado de um breakdown é sempre imprevisível, não podendo ser determinado nem pelo organismo e nem pelo mundo. Nas palavras de Varela:

Nos dois casos extremos - a experiência humana durante os colapsos e o comportamento animal em momentos de transições comportamentais - nos defrontamos, de formas tremendamente diversas, é inegável, com uma questão comum: a cada colapso desses, a maneira pela qual o agente cognitivo será em seguida constituído não é nem decidida externamente nem simplesmente planejada. Ao contrário, trata-se de uma questão de emergência segundo o senso comum da configuração autônoma de uma postura apropriada. Uma vez selecionada uma postura comportamental ou gerado um micromundo, podemos analisar de forma mais clara seu modo de operação e sua estratégia ótima (VARELA, 2003, p. 78).

Em havendo perturbação, duas possibilidades se colocam. Pela primeira, é possível que se estabeleça uma interação inovadora ou inventiva entre organismo e meio, havendo um novo acoplamento estrutural, ocorrendo mu- danças no domínio estrutural de ambos, uma vez que eles são co-definidos. A outra alternativa é a de uma interação destrutiva. Após a perturbação, organismo e meio entram em variação, contudo há uma destruição da organização minimal, ou seja, da autopoiese, rompendo dessa forma a manutenção da vida (MATURANA; VARELA, 1995).

Embora reconhecesse os avanços no campo científico possibilitados pelo conceito de autopoiese, Varela ainda a considerava uma alternativa fraca (COSTA, 1993). Para ele, era preciso enfatizar de modo definitivo o coengendramento organismo-meio, bem como a corporificação do conhecimento. A autopoiese poderia, segundo ele, acabar conduzindo a uma leitura solipsista. A postura solipsita ou idealista encontra-se no extremo oposto à objetivista ou representacional. Toda vez que evitamos o extremo representacional, o solipsismo aparece como risco. Ele constitui o pólo da extrema solidão cognitiva. Nas palavras de Maturana e Varela (1995, p. 164): “Dentro da tradição da filosofia clássica corresponde a afirmação de que só existe a interioridade de cada um". Com esta proposta, após trabalhar com a idéia de autonomia, Varela desenvolve a abordagem enativa. Enação constitui um neologismo inspirado no termo inglês enact que significa trazer à mão ou fazer emergir (MATURANA; VARELA, 1997) ${ }^{2}$. Assim conhecer é enagir a partir da ação, sujeito e mundo. A enação abarca as questões colocadas pela autopoiese, inclusive o seu mecanismo, porém destaca o aspecto da autonomia, ressaltando o não fundamento e, frisando noções como co-engendramento, circularidade e criação simultânea do sujeito e do mundo. Destacamos que a aposta no não fundamento não implica no relativismo. Embora o conhecimento não seja guiado por nenhum fator externo, ele é resultado da co-determinação, onde o encontro da estrutura do meio com a estrutura do vivo (acoplamento estrutural) limita os passos seguintes.

Com a abordagem autopoiética-enativa aprendemos que não existe o mundo, mas mundos. Nas palavras de Varela (2003, p. 79):

$2 \mathrm{Em}$ alguns textos esse termo é traduzido pela palavra atuação (VARELA; THOMPSON; ROSCH, 2003). Atuação como aquilo que é trazido à cena pela ação. Contudo, optamos por utilizar o neologismo enação, uma vez que a palavra atuação em português pode ser confundida com representação, e é justamente contra a representação que a enação se afirma. 
“A realidade não é projetada como algo dado: ela é dependente do sujeito da percepção, não porque ele a 'constrói' por um capricho, mas porque o que se considera um mundo relevante é inseparável da estrutura do percipiente". Portanto para o organismo existe apenas mundos de sentido, repletos de saliências enatuadas durante a sua história em função dos acoplamentos estabelecidos. Varela e Depraz (2002) introduzem o conceito de valência para explicar essa dimensão valorativa e afetiva que perpassa a atividade viva e cognitiva. Segundo os autores, os afetos não são colorações da cognição. Não se trata de um epifenômeno. Estão inextrincavelmente ligados ao ato cognitivo e à vida, na medida em que não se vive ou se conhece no vazio ou na harmonia plena. A vida só é vida numa certa tensão. Assim como a cognição, que requer um campo em que forças se polarizam, produzindo movimento. Note-se que este campo de forças é estabelecido pelo próprio viver e conhecer. A possibilidade de ser afetado por essas forças pressupõe uma abertura ao presente e à alteridade. Varela e Depraz (2002) defendem que esta abertura está na origem da experiência, da vida e da cognição na medida em que é responsável por colocar o vivo em movimento sem deixá-lo fixar numa estrutura rígida. Sobre o conceito de valência Varela e Depraz (2002, p. 153) afirmam tratar-se de uma "[ . . . ] polaridade dinâmica que se manifesta como uma tensão que assume várias formas: gosto - não gosto, atração - rejeição, fazer - desfazer [ . . . ]" de base pré-egoica. A relação organismo-meio é perpassada por uma atribuição de valores que é estabelecida em um plano pré-reflexivo e pré-egoico. Por tudo isso, com Maturana e Varela, a adaptação não pode ser entendida como passividade, adequação ou conformação, requerendo uma atividade. Trata-se de uma postura ativa diante desse campo de forças heterogêneas.

Segundo Varela os temas evolutivos caminham em paralelo aos comentários e críticas acerca da cognição (VARELA; THOMPSON; ROSCH, 2003, p. 191). Do mesmo modo que a idéia de representação (forte) está na base da maioria das ciências cognitivas, também o tema da adaptação entendida como ajustamento ou otimização ainda constitui a perspectiva dominante nos estudos da biologia evolutiva (VARELA; THOMPSON; ROSCH, 2003). Pensar a adaptação sob o ponto de vista autopoiético- enativo consiste em recusar a idéia de representação, de otimização e de adequação. Pois a vida não caminha em direção a algo, mas define seus caminhos no viver. Nas palavras de Maturana e Varela (1995, p. 201): "Viver é ação efetiva no existir como ser vivo". Ou ainda: "Na verdade, a vida ordinária, a vida de todos os dias, é uma refinada coreografia de coordenações comportamentais" (MATURANA; VARELA, 1995, p. 252).

Em contraposição à concepção darwinista que pensa a adaptação subordinada à seleção natural, a abordagem autopoiética-enativa sugere concebê-la como resultado de uma deriva natural. A noção de seleção pelo meio ambiente traz consigo as idéias de escolha e de um mundo pré-existente. Sem entrar no mérito da questão da seleção pelo meio das formas adaptadas, mas nos centrando na idéia de um mundo dado antes do vivo, vemos o quanto é difícil trabalhar com essa noção sob a perspectiva autopoiética-enativa. Como mundo e organismo são inventados em um mesmo movimento, a evolução é concebida como deriva. Maturana (1998) usa a metáfora da dança para explicar a deriva natural. Segundo ele é como se organismo e meio estivessem dançando de forma congruente. Não se trata de seleção, mas de composição ou sintonia. Ao invés de falar que as formas vivas atuais conseguiram resolver os problemas apresentados pelo meio, sendo portanto selecionadas, afirma-se que elas conseguiram satisfazer as condições mínimas colocadas no encontro com seu meio (VARELA; THOMPSON; ROSCH, 2003).

Com a abordagem autopoiética-enativa inverte-se a forma de explicar a vida. Passamos de uma lógica prescritiva para uma proscritiva (VARELA; THOMPSON; ROSCH, 2003). A lógica prescritiva afirma que aquilo que não está permitido, está proibido. Já a proscritiva considera que aquilo que não está proibido, está permitido. Desse modo a questão da adaptação deixa de ser conseqüência de uma otimização de formas, passando a admitir todas as formas viáveis ou satisfatórias. Citamos Varela, Thompson e Rosch (2003, p. 201): “Essa orientação proscritiva chama nossa atenção para a tremenda diversidade das estruturas biológicas em todos os níveis". O meio não se configura como inimigo contra o qual a vida é afirmada, passando a ser apenas uma alteridade que contribui para a manutenção do movimento da vida e da diversidade, ao possibilitar 
interações inventivas.

A possibilidade de ressignificação do conceito de adaptação a partir dessa abordagem depende então das idéias de autopoiese, autonomia e de co-engendramento sujeito-mundo. I sso significa que não existe um meio ambiente dado, fixo e único e nem organismos que são lançados violentamente nesse espaço prédado. Se a vida não tem outra finalidade senão o viver, é um erro considerar que o central nas condutas sejam suas conseqüências (MATURANA, 1998). A adequação, o sucesso ou o fracasso de uma conduta só existe do ponto de vista do observador (MATURANA; VARELA, 1995). Em toda descrição é preciso assumir a impossibilidade de objetividade, uma vez que o observador não pode adotar uma metaposição onipresente e onisciente. Não é possível conhecer a vida a não ser a partir de nós mesmos enquanto vivos, até porque nós somos o que vivemos e o que conhecemos. Dessa forma, toda descrição realizada por um observador pressupõe certas regularidades adotadas no presente por ele, sendo portanto situada no tempo e no espaço. Observador e organismo além de se constituírem diferentemente, em função de suas histórias de interações e acoplamentos, encontram-se em posições diferenciadas. Considerando tais advertências, como observadores, nos é permitido um acesso peculiar à cena de interações organismo - meio. Maturana e Varela (1995, p. 136) comentam a respeito do ponto de vista do observador: "Por um lado, temos acesso à estrutura do meio e, por outro, à estrutura do organismo. Podemos considerar as várias maneiras com que ambas poderiam ter mudado ao se encontrarem, caso as interações tivessem sido diferentes das que efetivamente ocorreram". Tendo em vista esta colocação pensamos que na maioria das vezes julgamos o domínio experiencial do vivo a partir do ponto de vista do observador. Situados externamente, especulamos a respeito do que ele deveria ou não ter feito. Tal atitude ignora a autonomia própria do vivo.

Portanto, através da abordagem autopoiética-enativa nos aproximamos de uma concepção de adaptação como uma sintonia ou co-engendramento local e momentâneo entre organismo e meio, ou entre sujeito e mundo. A adaptação surge como conseqüência dos acoplamentos estruturais, sendo limitada exclusivamente pela manutenção da autopoiese. Ela inclui a incorporação da idéia de breakdown como fun- damental para a manutenção da adaptação. Se a única restrição para a adaptação é o rompimento da capacidade de reinventar-se a si e ao mundo, essa não pode efetuar-se de modo definitivo, mas apenas como processo. Conceber a adaptação como adequação ou ajustamento implicaria em desconsiderar a autonomia do vivo, bem como ignorar o seu sentido biológico, isto é sua dimensão viva e inventiva. Logo, a adaptação como adequação, ao invés de garantir a sobrevivência, conforme postula a teoria adaptacionista ou darwinista, implicaria, sob o ponto de vista autopoiético-enativo, na morte do organismo. Parece, portanto, que se quisermos continuar trabalhando com o conceito de adaptação precisaremos tomá-lo em sentido fraco, analogamente ao conceito de representação (SANCOVSCHI, 2003). A adaptação em sentido fraco não é uma adaptação inferior, ao contrário, a potência deste conceito encontra-se em seu sentido fraco. A adaptação em sentido fraco seria conseqüência do viver inventivo, uma forma de acoplamento que não extinguiria a processualidade viva. Implicaria então em uma normatividade produtora de sujeitos singulares e não em uma normalidade pasteurizada da vida. A vida sem alteridade é uma vida sem perturbações, sem desvios ou derivas, sem movimentos e sem afetos, sem valências, ou seja é uma vida destituída de força ou potência vital.

\section{Por uma Adaptação em Sentido Fraco: implicações para a Psicologia}

A partir da recusa da representação e, enfatizando a autonomia do vivo, Maturana e Varela nos auxiliam na construção de uma concepção da adaptação em sentido fraco. O adjetivo fraco não possui conotação negativa, mas é responsável pela positividade do conceito. A adaptação em sentido fraco segue a lógica proscritiva que postula uma sintonia ou co-engendramento local e momentâneo entre organismo e meio, ou entre sujeito e mundo. Conseqüência dos acoplamentos estruturais, é limitada apenas pela manutenção da autopoiese. A única restrição para a adaptação é a perda da capacidade de reinventar-se a si e ao mundo. Por isso a adaptação não pode se estabelecer de modo definitivo, mas apenas como processo. Assim essa noção é inseparável da de breakdown, apontando para um 
desarranjo na base da adaptação. Uma disfuncionalidade que não se dá por uma falta ou carência, mas que faz parte do funcionamento adaptado. Desse modo a adaptação não tende a uma forma ótima, equilibrada e estável, mas pressupõe a alteridade e a perturbação. Estas garantirão a ela sua potência viva. A alteridade refere-se ao fato de que a adaptação se estabelece em um campo de forças. Neste sentido ela deve ser concebida como uma postura ativa diante de uma multiplicidade de forças, com manutenção da autopoiese. A alteridade também comparece como resultado das adaptações. Adaptar-se não é conformar-se, mas diferir de si e dos outros em um movimento congruente com seu mundo. A adaptação em sentido fraco é, então, uma adaptação viva.

Portanto, adaptação não é sinônimo de ajustamento. A afirmação da psicologia enquanto ciência comprometida com a adaptação não implica necessariamente em práticas normalizadoras. Se, ao invés de definirmos a adaptação como adequação de um sujeito a um mundo pré-existente, usarmos a definição autopoiética-enativa, - adaptação como produção de uma forma de vida congruente com o mundo - , então, no lugar de práticas normalizadoras a psicologia deverá adotar práticas inventivas e criadoras. Ao invés de práticas homogeneizantes que conformam os sujeitos deixando de lado sua potência viva, a psicolo- gia deverá investir em práticas que considerem a dimensão normativa destes. Em outras palavras, em práticas que levem em consideração a capacidade do vivo de inventar regras e/ou normas para viver. Ressaltamos que a aposta na normatividade e na autonomia não significa que qualquer coisa seja possível. A normatividade e a autonomia acontecem a partir de um co-engendramento entre sujeito e mundo. Assim toda a regra criada trará a marca do constrangimento do sujeito e do mundo. A adaptação pressuporá a errância, as perturbações, os breakdowns ou ainda as disfuncionalidades que são próprios da vida. Podemos falar em uma sintonia, em uma composição, mas não em conformação, ajustamento ou adequação. A psicologia sensível às contribuições da abordagem autopoiética-enativa proporá em suas práticas não formas ideais às quais os indivíduos devem conformar-se, mas possibilidades de transformação, possibilidades de construção de novas subjetividades. No lugar de normas e/ou regras dadas, normas e regras coengendradas nos encontros entre os sujeitos e seus mundos. Gostaríamos de encerrar destacando que essa revisão conceitual traz com ela importantes implicações éticas e políticas. Trabalhar com uma concepção de adaptação como ajustamento ou, com uma concepção de adaptação como co-engendramento torna-se uma questão ético-política.

\section{Referências}

ALVAREZ, J. Por um Construtivismo Radical: a cognição e o tempo a partir dos estudos da epistemologia genética e da teoria da autopoiese. 1999. Dissertação (mestrado) - Instituto de Psicologia, Universidade Federal do Rio de Janeiro, 1999, Rio de Janeiro, BR-RJ.

CANGUI LHEM, G. O que é a Psicologia? Tempo Brasileiro, Rio de Janeiro, n. 30/31, p. 104-123, jul./dez. 1973. Título do fascículo: Epistemologia 2.

CANGUI LHEM, G. El conocimiento de la vida. Barcelona: Ed. Anagrama, 1976.

CANGUI LHEM, G. O Normal e o Patológico. Rio de Janeiro: Forense Universitária, 1982.

FERREIRA, A.L.; GUTMAN, G. O Funcionalismo em seus Primórdios: a Psicologia a serviço da adaptação. In: J ACÓ-VILELA, A.; FERREIRA, A.; PORTUGAL, F. História da Psicologia: rumos e percursos. Rio de Janeiro: Nau Ed., 2005. p.121.140.

FIGUEIREDO, L.C. Revisitando as Psicologias: da epistemologia à ética das práticas e discursos psicológicos. In: FIGUEIREDO, L.C. Os Lugares da Psicologia. São Paulo: Vozes, 1995. p.13-33.

FIGUEIREDO, L.C.; SANTI, P.L. Psicologia, uma (Nova) Introdução: uma visão histórica da psicologia como ciência. São Paulo: Educ, 2002. 
KASTRUP, V. A Invenção de Si e do Mundo: uma introdução do tempo e do coletivo no estudo da cognição. Campinas: Papirus, 1999.

KASTRUP, V.; TEDESCO, S.; PASSOS, E. Políticas da Cognição. Porto Alegre: Sulina, 2008.

MATURANA, H. De Máquinas e Seres Vivos: autopoiese a organização do vivo. Porto Alegre: Artes Médicas, 1997.

MATURANA, H. Reflexões: aprendizagem ou derivação ontogênica? In: MATURANA, H. Da Biologia à Psicologia. Porto Alegra: Artes Médicas, 1998. p.31-47.

MATURANA, H. A Ontologia da Realidade. Belo Horizonte: Ed. UFMG, 2001.

MATURANA, H.; VARELA, F. A Árvore do Conhecimento. Rio de janeiro: Ed. Psy II, 1995.

PATTO, M.H. Psicologia e Ideologia: uma introdução crítica à psicologia escolar. São Paulo: T.A Queiroz, 1987.

SANCOVSCHI, B. Sobre o Caminho dos Riscos: repensando o conceito de adaptação. 2003. Monografia apresentada como trabalho de conclusão no Curso de Graduação de Psicologia, Instituto de Psicologia, Universidade Federal do Rio de Janeiro, 2003, Rio de Janeiro, BR-RJ.

SANCOVSCHI, B. Sobre a Aprendizagem: ressonâncias entre a abordagem enativa de F. Varela e a psicologia histórico-cultural de L.S. Vygotski. 2005. Dissertação (mestrado) - Instituto de Psicologia, Universidade Federal do Rio de Janeiro, 2005, Rio de Janeiro, BR-RJ.

SANCOVSCHI, B. Sobre a Noção de Representação em S. Moscovici e F. Varela. Psicologia \& Sociedade, Belo Horizonte, v. 19, n. 2, p. 7-14, 2007.

SANCOVSCHI, B.; KASTRUP, V. Algumas Ressonâncias Entre a Abordagem Enativa e a Psicologia HistóricoCultural. Fractal: revista de Psicologia, Niterói, v. 20, n. 1, p. 165-181, 2008.

SCHULTZ, D.; SCHULTZ, S.E. História da Psicologia Moderna. São Paulo: Cultrix, 1992.

VARELA, F. A Individualidade: a autonomia do ser vivo. In: VEYNE, P.; VERNANT,J.P. et.al. Indivíduo e Poder. Lisboa: Ed. 70, 1988. p.105-112.

VARELA, F. Autonomie et connaissance: essai sur lê vivant. Paris: Seuil, 1989.

VARELA, F. Conhecer: as ciências cognitivas tendências e perspectivas. Lisboa: Instituto Piaget, 1990.

VARELA, F. Entrevista. In: COSTA, R. Limiares do Contemporâneo: entrevistas. São Paulo: Ed. Escuta, 1993. p. 77-97.

VARELA, F. O Reencantamento do Concreto. Cadernos de Subjetividade, São Paulo, v. 1, n. 1, p. 72-86, 2003.

VARELA, F.; DEPRAZ, N. At the saurce of time: valence and the constitutional dynamics of affect. 2000. Disponível em: <http://www.liane.net/aerobase> Acesso em: mar. 2002.

VARELA, F.; THOMPSON, E.; ROSCH, E. A Mente Incorporada: ciências cognitivas e experiência humana. Porto Alegre: Artmed, 2003.

Recebido em agosto de 2009

Aprovado para publicação em setembro de 2009

\section{Beatriz Sancovschi}

Doutoranda do programa de Pós-Graduação em Psicologia da UFRJ, bolsista CNPq

email: biasan@hotmail.com 